\title{
Relationship between urban green spaces and other features of urban morphology with traffic noise distribution
}

\author{
Efstathios Margaritis ${ }^{\mathrm{a}}$, Jian Kang ${ }^{\mathrm{a} *}$ \\ ${ }^{a}$ School of Architecture, University of Sheffield, Western Bank, Sheffield S10 2TN, United \\ Kingdom
}

* Corresponding author

\begin{abstract}
The effect of greenery on traffic noise mitigation has been extensively studied on the level of single plants, green walls, berms and hedges, but not considering whole sample areas within the cities. Therefore, the aim of this paper is to investigate the relationship between features of urban morphology related to green spaces, roads or buildings and traffic noise distribution in urban areas. The analysis was applied in eight UK cities with different historical and architectural background, following two different settlement forms (radial, linear). In each city a $30 \mathrm{~km}^{2}$ grid was defined and three different levels of approach were considered (macro-scale, meso-scale, micro-scale). The first level regarded the eight cities as single entities, while in the second one every single tile of the applied grid was investigated in two different cities. In the third level only the eight city centres were analyzed. Statistical analysis was used combined with GIS tools. In total 18 variables were constructed and tested for possible relationships with noise levels $\left(L_{\text {den }}\right)$. It was found that in spite of the fact that each city has its own dynamic and form, features of urban morphology were related to traffic noise levels to a different extent at each scale. At the macro-scale, the green space pattern was related to the structure of the city as well as the traffic noise levels in combination with the rest of the morphological parameters. At the meso-scale, an increase in internal road connectivity contributed to higher traffic noise. Green space variables explained part of the variance in traffic prediction models. Finally, at the micro-scale, it was also proved that different areas can have the same building coverage but different noise levels. Therefore, these indexes could be profiled and used as an "a priori" tool for urban sound planning.
\end{abstract}

Keywords: Macro-scale, Meso-scale, Micro-scale, Noise map, Pattern analysis, Spatial statistics

2016 Urban Forestry and Urban Greening

Date Received: 24 March 2015 Date Accepted: 21 December 2015

Available online: 29 December 2015 


\section{Introduction}

Traffic noise is an increasing problem in the contemporary society and the prevalent noise source in the urban environment (Quis,1999). About 210 million people, over $44 \%$ of the EU population, are regularly exposed to levels over $55 \mathrm{~dB}(\mathrm{~A})$, a limit which has been recognized by the World Health Organization (WHO, 2011) to pose a serious risk to health. The Environmental Noise Directive (END) (2002/49/EC) and the supplementary noise action plans set the base for developing community measures for noise reduction emitted by major sources.

The generic structure of urban morphology, according to Kropf (2005), is a hierarchy of different characteristics at different interdependent scales involving (a) building elements, (b) road infrastructure and (c) land use components. In this network green spaces have a direct and dynamic relationship with the urban structure (Ståhle, 2010).

Previous studies have put emphasis on diverse building arrangements or formations (Oliveira and Silva, 2010; Guedes et al., 2011; Salomons and Berghauser Pont, 2012; Silva et al., 2014; Lee and Kang, 2015). Others focused more on a dwelling scale within the same or different cities (Wang and Kang, 2011; Hao and Kang, 2013; Lam et al., 2013; Hao et al., 2015a). However, in the urban scale, morphological parameters have been investigated to a lesser extent in connection with traffic noise (Tang and Wang, 2007; Salomons and Berghauser Pont, 2012) and more as part of the urban sprawl process (Galster et al., 2001; Knaap et al., 2005; Tsai, 2005) or land use attributes (Chakraborty, 2009; Kashem et al., 2009).

The accepted definition of urban green spaces by scientists of different backgrounds refers to public and private open spaces in urban areas covered by vegetation directly or indirectly available for the users (Haq, 2011). This broad category includes mainly parks, forests, public squares, recreational grounds and private front or backyard garden land. Ongoing interdisciplinary research is being carried out; either emphasizing the effect of vegetation non traffic noise in terms of trees, plants and hedges (Kragh, 1981;Huddart, 1990; Van Renterghem and Botteldooren, 2002; Fang and Ling, 2005; Kang, 2007; Wong et al., 2010; Pathak et al., 2011;Yang et al., 2011; Horoshenkov et al., 2013; Van Renterghem et al.,2014) or studying the acoustic properties of the ground in terms of porosity and other similar parameters (Attenborough, 2002;Gołebiewski, 2007; Attenborough et al., 2012; Bashir et al., 2015).

Previous work has put emphasis on individually assessing the effectiveness of parks on traffic noise reduction (González-Oreja et al., 2010; Cohen et al., 2014). However, in these cases the weight was put more on the contribution of greenery in soundscape perception (Nilsson and Berglund, 2006; Margaritis et al., 2015) and not in the distinction between rigid and porous ground as a land use element (European Commission, 2007). Similarly on the urban scale, green space patterns have previously been investigated using various spatial metrics (McGarical and Marks, 1994; Liu et al., 2014). Nevertheless, these indexes do not provide any statistical significance for the degree of clustering or dispersion of the pattern. The latter can be measured by two metrics: (a) the centroid-based Average Nearest Neighbour index (ANN) and the edge-based Connectivity index calculated by the Conefor software (Saura and Torné, 2009).

The street pattern, as a component of the urban morphology, gives a specific identity to each city. In particular, "settlement form" can be used as a term to describe the network structure of distinct units such as cities and towns (Marshall and Gong, 2009). For planning purposes at a city-scale level, Lynch and Hack (1962) proposed three simple systematic 
patterns/forms: radial, linear and grid. In radial patterns, a main ring road acts as the area constraint around built-up areas, while linear patterns refer to developments, laid out along a transportation 'spine' (Marshall and Gong, 2009). In the same level, Marshall (2005) recognized over 100 descriptors related to street patterns. Nevertheless, all the derivative patterns fall back into the neat sets of rudimentary typologies (radial, grid, linear).

The aim of this paper is therefore to quantitatively investigate the relationship between features of urban morphology and traffic noise distribution with special emphasis on urban green spaces. The historical and architectural background of the cities was also investigated as a complementary element. However the main emphasis was to quantify the present conditions. A triple level analysis was conducted on a macro, meso and micro-scale. For the macro-scale, three targets can be identified: (a) the relationship between urban morphology and traffic noise, (b) the relationship between green space ratio, green space pattern and traffic noise with the settlement forms and (c) the effect of street typology on traffic noise distribution. In the meso and micro-scale the aim is to identify and assess the effectiveness of indicators related to urban morphology in traffic noise distribution.

As regards the scales of interest, the macro-scale refers to the consideration of the city as an entity where the entire sample area is represented by a single value per variable. In the meso-scale, each variable is calculated separately for each one of the 30 tiles of the grid. Finally, in the micro-scale, the analysis is conducted within a single tile from each city.

\section{Materials and Methods}

\section{Study sites}

In the first part, a macro-scale analysis was conducted among eight cities of different settlement form according to the classification proposed by Marshall (2005). As shown in Fig. 1 the first four cities, grouped as "radial", (Coventry, Leicester, Nottingham, Sheffield) contain a main urban core surrounded by a circumferential road system. The remaining four (Bournemouth, Blackpool, Southend, Brighton) were grouped as "linear", since their structure is based on a few main vertical or horizontal arteries. The analysis was restricted within the boundaries of the first agglomeration level, which is equal to, or smaller than, the official administrative ones. 


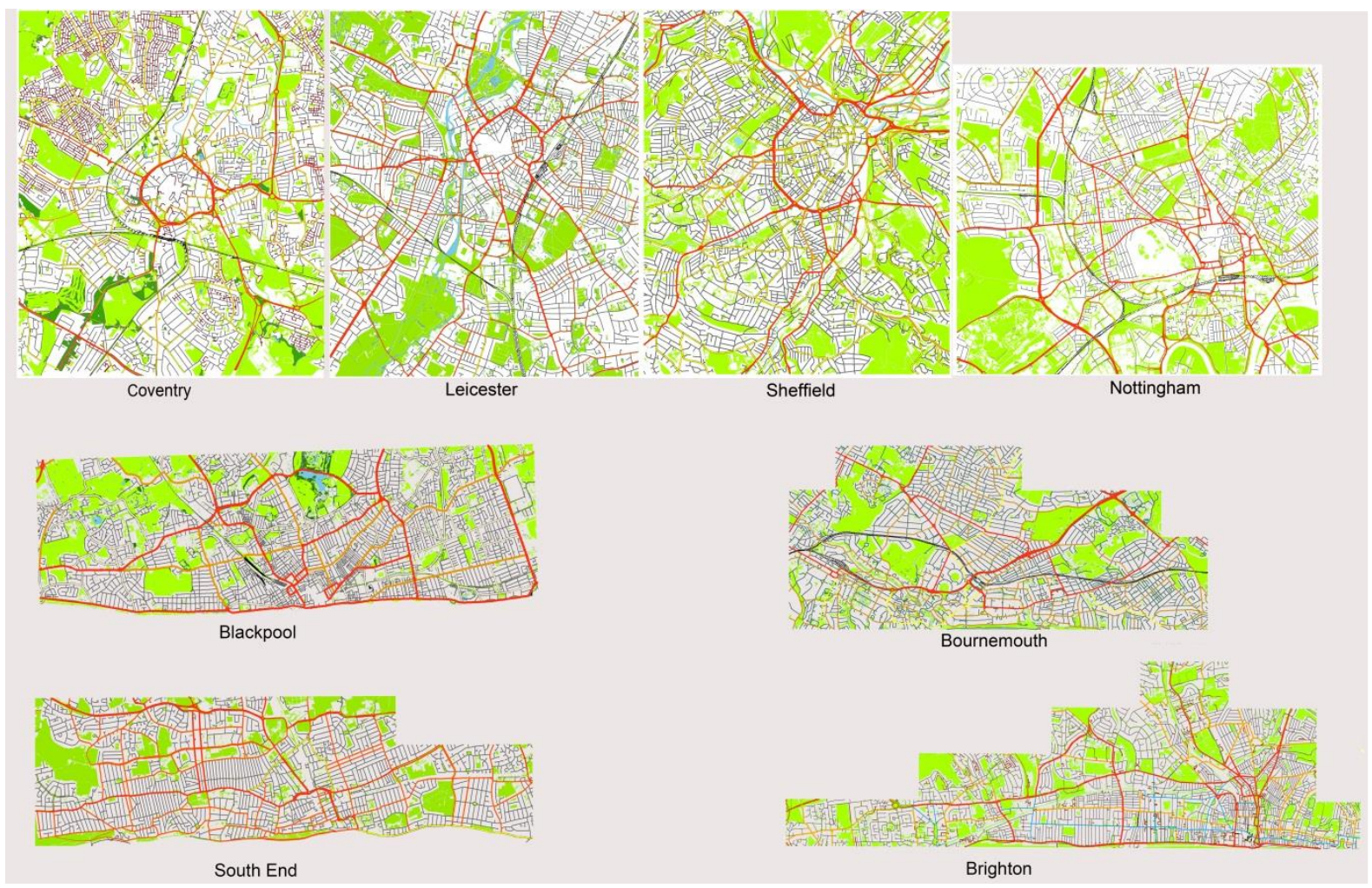

Fig. 1. Green space distribution in radial and linear settlement forms

In the second part, a deeper meso-scale analysis was conducted between a radial and a linear city; Sheffield and Brighton. Sheffield, apart from being one of the greenest cities in UK (Sheffield City Council, 2010), has many similarities with Brighton in terms of land use. Specifically the two sample areas have almost the same percentage of Building Coverage, Road Coverage and porous surfaces including yards and parks. Finally, in the micro-scale level a detailed comparison is performed using the same methodology and variables trying to classify the city centres according to their morphological characteristics.

Historically, most of the cities such as Coventry, Nottingham, Brighton, Southend and Leicester date back to the 5th-7th AD or earlier as Anglo-Saxon or Celtic settlements. On the contrary, Sheffield and Bournemouth have a more recent history since they were founded in early 12th and 19th century respectively (Local Histories, 2015). In the old times, all of the radial cities had a fortified settlement surrounding for defensive purposes. This is a possible reason for the ring road structure, which was developed in the later years. Great changes took place after World War II in the urban structure of every city leading to the regeneration of many areas and Council House development between 1920and 1960. At the same period public green spaces become officially protected as a response against industrialization and town expansion.

In terms of population dynamics it can be seen in Fig. 2a that all radial cities outgrow the linear ones with an average size of 380,000 inhabitants compared to 190,000 inhabitants (Office for National Statistics, 2011). Historically, Nottingham and Sheffield reached the threshold of 150,000 residents in the beginning of 19th century, while the majority of cities were in the same position between 1930s and 1960s apart from Bournemouth (Fig. 2a). However, a comparison among them is feasible since they are mostly average-sized cities with similar population size within the sample areas $(M=160,000$, S.D. $=28,000)$ as shown in Fig. 2b. 

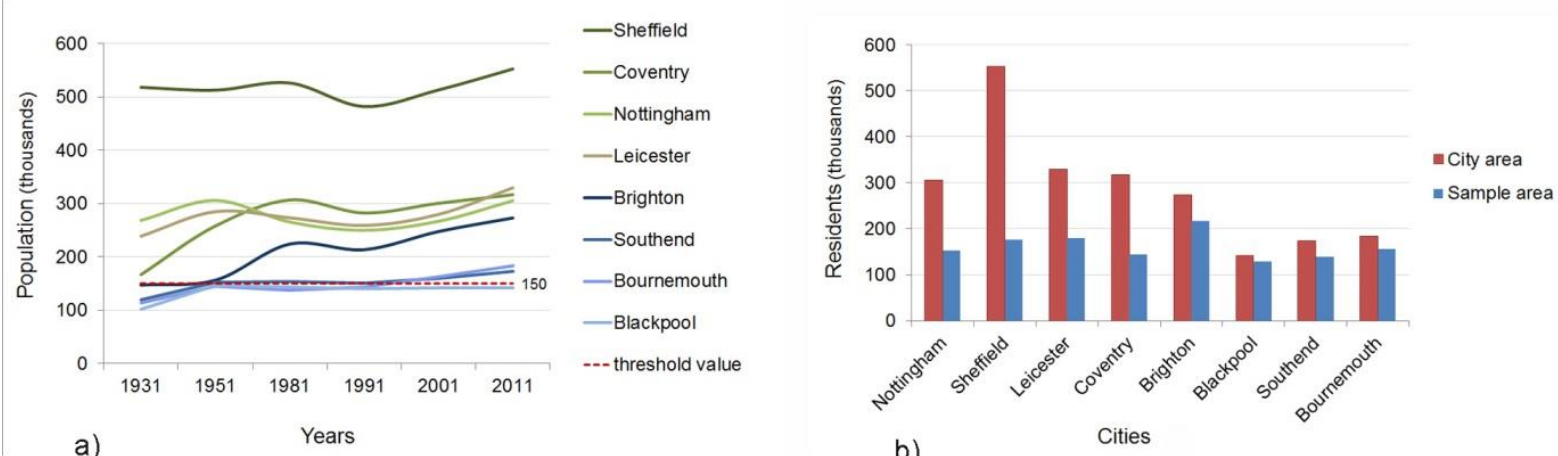

Fig. 2. (a) Population evolution since 1930, (b) Population comparison between cities in the Local Authority level and sample areas (2011).

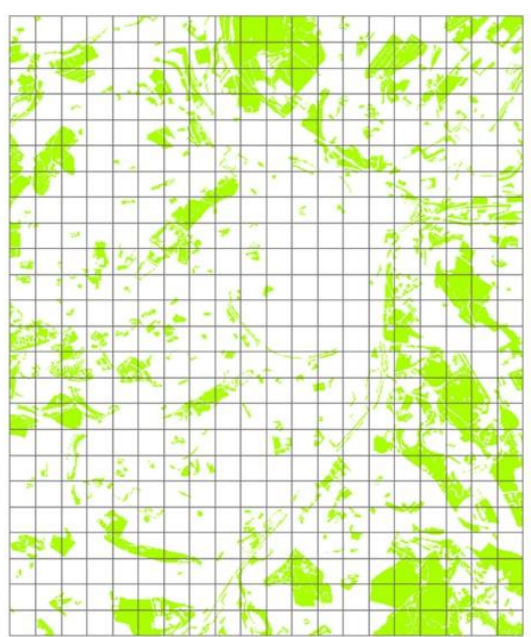

a)

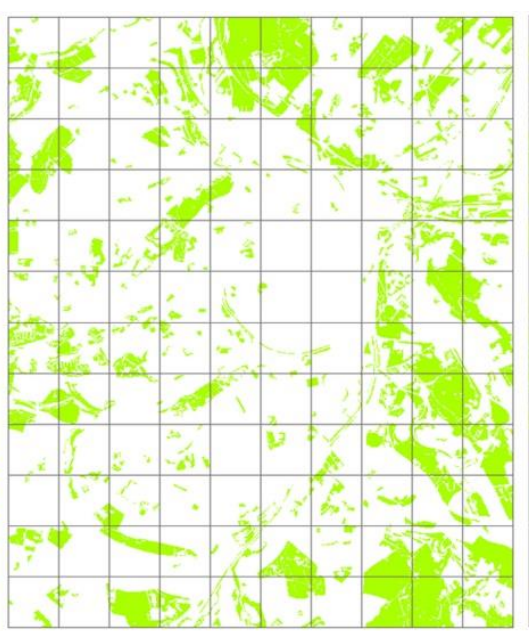

b)

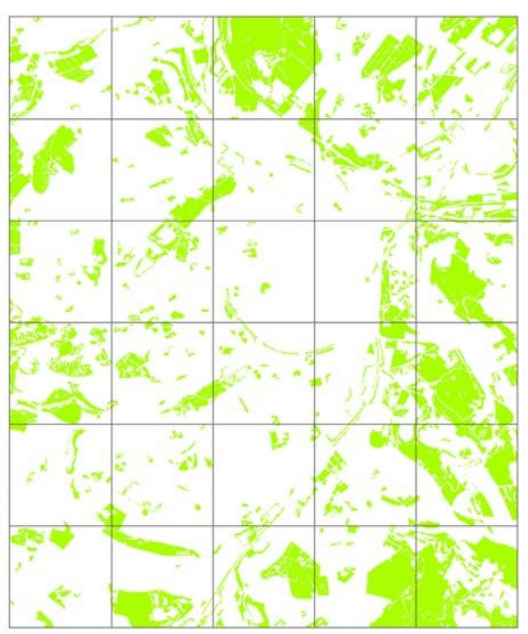

c)

Fig. 3. Possible grid sizes and respective coefficients of determination $\left(R^{亡}\right)$ between green space ratio and noise levels $\left(L_{\text {den }}\right)$ tested in Sheffield: (a) $250 \mathrm{~m} \times 250 \mathrm{~m}-\mathrm{R}^{2}=.07$, (b) $500 \mathrm{~m} \times 500 \mathrm{~m}-\mathrm{R}^{2}=.037$, (c) $1000 \mathrm{~m}$ $\times 1000 m-R^{2}=.285$.

\section{Sample and grid size selection}

The sample area in each city at both scales (macro, meso) was defined by a grid, placed so as to include the broad city centre and the nearby areas. Another criterion was to place the grid in such away so as to cover as many "solid" areas as possible, since many parts close to the agglomeration borders appeared vacant with no data. Only tiles of less than $10 \%$ of missing data were considered valid. Finally, in the micro-scale approach, central areas that accumulate a great variety of services and are usually considered as the "heart" of the city were chosen for the analysis.

The grid resolution was calculated in advance through, three different linear regression tests considering tiles of $250 \mathrm{~m}, 500 \mathrm{~m}$ and $1000 \mathrm{~m}$ as presented in Fig. 3. Results proved that the highest coefficient of determination $\left(R^{2}\right)$, between the ratio of all green spaces and noise levels per tile, occurred with the $1000 \mathrm{~m}$ tile $\left(R^{2}=.29, p<.05\right)$. As a result the selected tile size was $1 \mathrm{~km} \times 1 \mathrm{~km}$. The sample size was then calculated using a G-Power test for a multiple regression fixed model. The appropriate sample size aiming at a variance of over $70 \%$ within a confidence level of $95 \%$ and three final predictors was 27 observations (GPower manual, 2014). Ultimately, the selected sample of 30 observations $\left(30 \mathrm{~km}^{2}\right)$ satisfied the above criterion. With the current resolution, the sample area can cover $38-88 \%$ of the total noise mapping area depending on the city. 


\section{Noise level data}

The data source for noise levels lies on the online noise maps for the first round agglomerations produced by the English Department for Environment Food and Rural Affairs (DEFRA, 2007). The current noise levels correspond to an average day over the whole year. For the current research this was 2006, since it is the year with the latest available public data. Additional data for land cover, ground elevation, meteorology and building heights are included in the official noise mapping process, but no in situ noise measurements. The final product is a $10 \mathrm{~m}$ grid raster dataset. As shown in Fig. 4, there are six noise classes of $5 \mathrm{~dB}$ each; ranging from 0 to $75+d B(A)$ using the $L_{\text {den }}$ and $L_{\text {night }}$ indices (END, p. 7). The maps have been produced for areas, which include a population of more than 250,000 residents and a population density of more than 500 persons $/ \mathrm{km}^{2}$. Since original data were not available for this research, each noise map was reconstructed from the beginning as a new raster dataset in the finest available resolution. The number of noise classes and the colour palette in the new file comply with DEFRA's legend (Fig. 4).

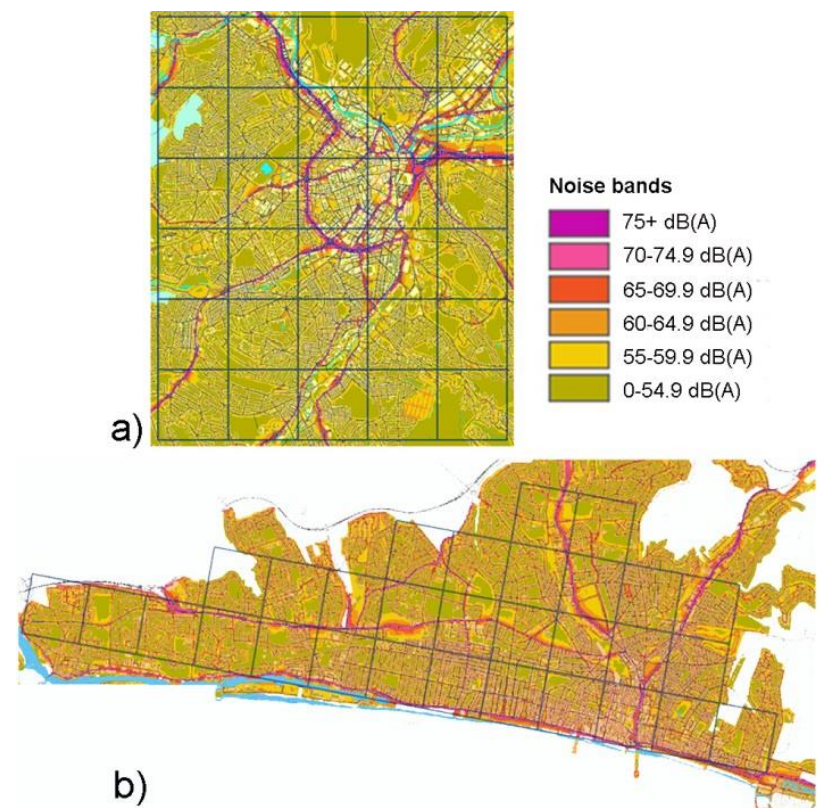

Fig. 4. Examples of noise maps with the applied grid of $1 \mathrm{~km}$ for: (a) Sheffield and (b) Brighton.

\section{Urban morphological data}

The vector 2D datasets related with the morphological parameters were extracted using the OS Mastermap Topography collection (Ordnance Survey, 2007) (1:1250). The same variables were calculated for all scales; nevertheless four variables were not available in the macro-scale and two in the meso and micro-scale. As reported in Table 1 three morphological categories can be distinguished according to their semantic content ("Green Space Ratio", "Green Space Pattern", "Buildings and Streets") and one called "Geodemographic".

Green spaces in this study are divided in two classes. The first class is called "Natural Urban Green" and refers to the ratio of parks, urban forests, public squares and recreational grounds in the sample area. The second class is classified as "Gardens" representing the areas of private front yards and backyards covered by grass and some small green areas 
between houses which do not belong to the first category. Finally, the two buffer-related variables comprise green areas from the first class within a buffer zone of $100 \mathrm{~m}$ around the two road categories. The aggregation of Natural Urban Green and Gardens represent the porous surfaces in the city. Respectively, the total amount of roads, buildings and other manmade structures account for the rigid surfaces.

Table 1

Explanation of variables per category and scale: data available at this scale (/), data not available at this scale (O).

\begin{tabular}{|c|c|c|c|c|}
\hline \multirow[t]{2}{*}{ Parameter } & \multirow[t]{2}{*}{ Explanation } & \multicolumn{3}{|l|}{ Scale } \\
\hline & & Macro & Meso & Micro \\
\hline \multicolumn{5}{|l|}{ Green Space Ratio } \\
\hline Natural Urban Green ratio & Ratio of green spaces that belong to the Natural Urban Green class & / & / & / \\
\hline Gardens ratio & Ratio of green spaces that belong to the Gardens class & $\mathrm{O}$ & / & I \\
\hline Primary Buffer Zone & Area of Natural Urban Green within 100m from Primary Roads & $\mathrm{O}$ & / & / \\
\hline Local Buffer Zone & Area of Natural Urban Green within 100m from Local Roads & $\mathrm{O}$ & / & / \\
\hline \multicolumn{5}{|l|}{ Green Space Pattern } \\
\hline $\begin{array}{l}\text { Average Nearest Neighbour (ANN) } \\
\text { index }\end{array}$ & $\begin{array}{l}\text { Centroid-based index measuring the extent of clustering or dispersion of green } \\
\text { space patches }\end{array}$ & / & / & / \\
\hline Conefor Connectivity index & $\begin{array}{l}\text { Edge-based index measuring the extent of connectivity among green space } \\
\text { patches }\end{array}$ & / & / & / \\
\hline \multicolumn{5}{|l|}{ Buildings and Streets } \\
\hline Building Coverage & Ratio of built surface compared to the total surface & / & / & / \\
\hline Building Perimeter & Total perimeter of all buildings & / & / & / \\
\hline Number of Buildings & Total number of buildings & / & / & / \\
\hline Road Coverage & Ratio of road surface compared to the total surface & / & / & / \\
\hline Primary Road Intersections & Number of street intersections in the Primary Roads & $\mathrm{O}$ & / & / \\
\hline Local Road Intersections & Number of street intersections in the Local Roads & / & / & / \\
\hline Primary Roads Length ratio & Ratio of Primary Roads Length to the total road network & / & / & / \\
\hline Secondary Roads Length ratio & Ratio of Secondary Roads Length to the total road network & / & $\mathrm{O}$ & $\mathrm{O}$ \\
\hline Minor Roads Length ratio & Ratio of Minor Roads Length to the total road network & / & / & / \\
\hline Local Roads Length ratio & Ratio of Local Roads Length to the total road network & / & / & / \\
\hline \multicolumn{5}{|l|}{ Geodemographic variables } \\
\hline Population & Number of residents, 2011 Census (Output Areas) & / & / & / \\
\hline Car Availability ratio & Ratio of cars per resident, 2011 Census (Output Areas) & I & / & l \\
\hline
\end{tabular}

The second category refers to the spatial pattern of Natural Urban Green. Shapes over 0.1 ha were used in order to remove the biased effect of small polygons. The Average Nearest Neighbour (ANN) index is expressed as the ratio of the observed distance (Do) among the centroids of the green patches divided by the expected distance $(D \varepsilon)$ in a hypothetical random distribution. A distance threshold value among the patches is not necessary to be defined by the user as in other pattern analysis tools. If the index is less than 1 the pattern exhibits clustering, while in the opposite case the trend is towards dispersion. Only statistically significant results were used within a significant level of $p<.01$. Finally, the Conefor Connectivity index calculates the total distance of all possible combinations among 
the patches divided by the number of combinations. Higher values of the index signify a tendency to dispersed patterns.

The third category consists of variables related to road categories (Ordnance Survey, 2014) and building attributes calculated on average values per tile. Height values have not yet been available from Ordnance Survey. Finally, the last category refers to geodemographic variables such as population and Car Availability ratio in the Output Areas (OA) according to the 2011 Census.

\section{Calculation of noise levels}

In the meso-scale each map was clipped in 30 smaller raster files in accordance with the borders of the tiles, while a single raster file was considered in the macro-scale. All noise indices $\left(L_{n}\right)$ were then calculated using a Matlab code, which converts the colour values per pixel $(R G B)$ in noise levels as presented in Fig. 5. Buildings, roads and inland water were attributed with a zero $\mathrm{dB}(\mathrm{A})$ value. A distinction should be made between the current noise levels, which are spatial $\left(L_{s n}\right)$ and the traditional time-based percentile sound levels $\left(L_{n}\right)$. $L_{s n}$ corresponds to the percentage of the pixel values. Consequently $L_{s 10}$ represents the $10 \%$ of all values, while $L_{s 90}$ represents the background noise or the $90 \%$ of the total data when these are sorted in a descending form. In the meso-scale, for each one of the 30 tiles all $L_{s n}$ noise indicators $\left(L_{s 10}, L_{s 90}, L_{s m i n}, L_{s m a x}, L_{\text {sdenavg }}\right)$ were calculated in both cities $O n$ the macroscale, there was one value per index calculated using the entire sample area $\left(30 \mathrm{~km}^{2}\right)$ without further tiling. The same process was repeated for the morphological variables.

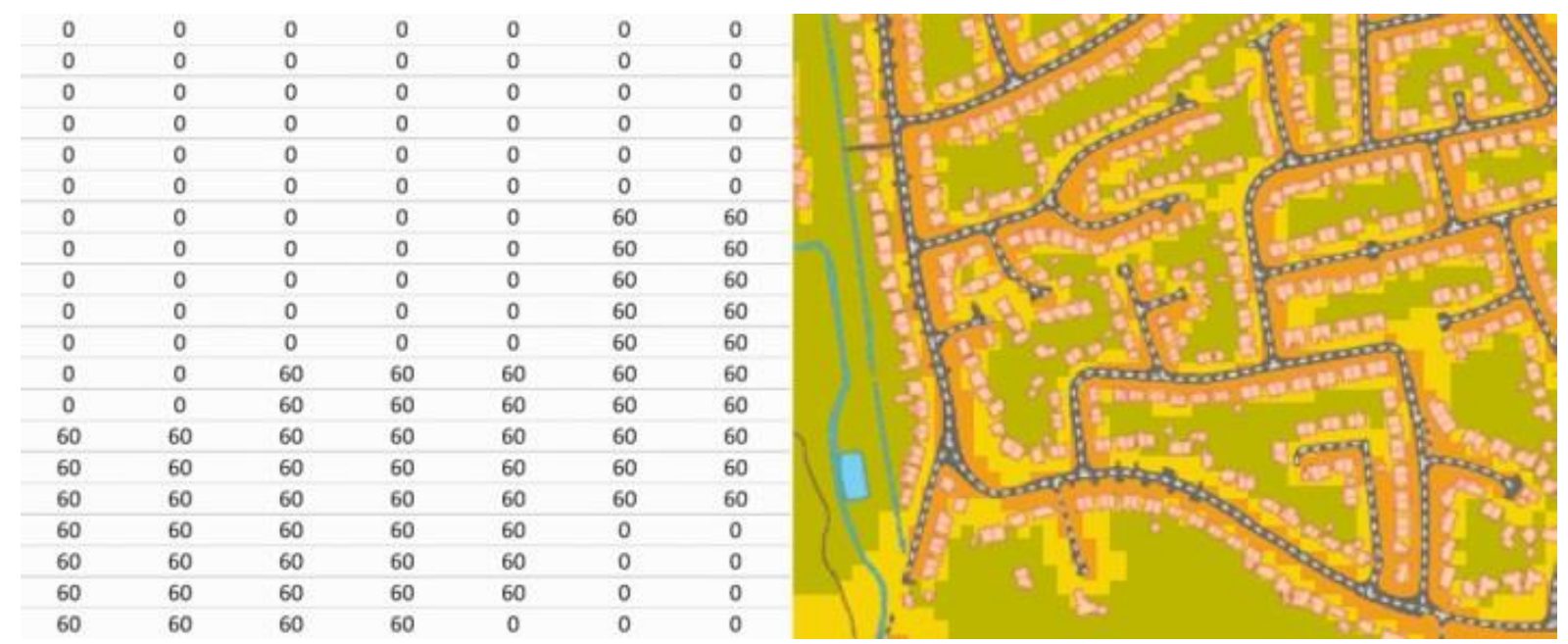

Fig. 5. Matlab code results presenting the transformation from RGB pixel values in $d B(A)$ levels.

\section{Calculation of morphological variables}

The calculation of this process was accomplished using ArcGIS (v.10.1) and the British National Grid coordinate system. In total sixteen morphological variables were tested in all levels and two extra geodemographic variables (Table 1). Indices related to Green Space Ratio were calculated using the Analysis toolbox, while street-related variables with the Network Analyst toolbox. Ultimately the Green Space Pattern was explored through the ANN and the Conefor Connectivity index. 


\section{Results}

\section{Macro-scale}

Correlations between urban morphology and traffic noise

A Pearson product-moment correlation coefficient was used to assess the relationship between the group of morphological variables and traffic noise levels for the eight cities. Results proved that two variables were found to be statistically significant in this level with the green space variables to be excluded. Firstly, there was a negative correlation between the ANN index and traffic noise $r(8)=-.71, p<.05$.

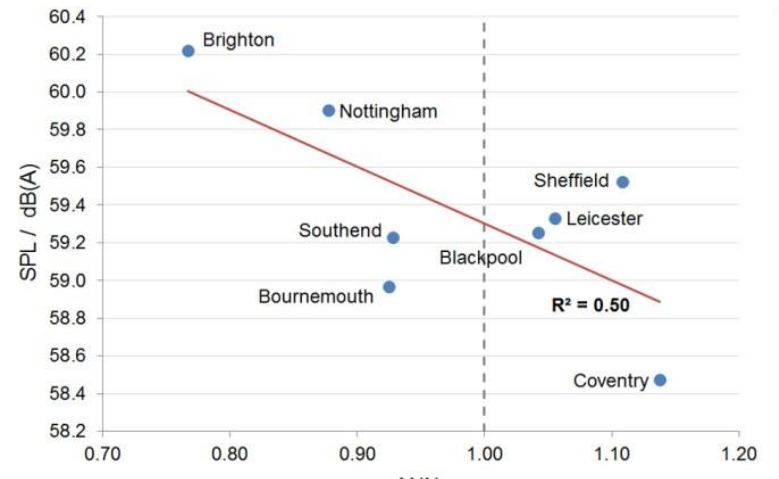

a)

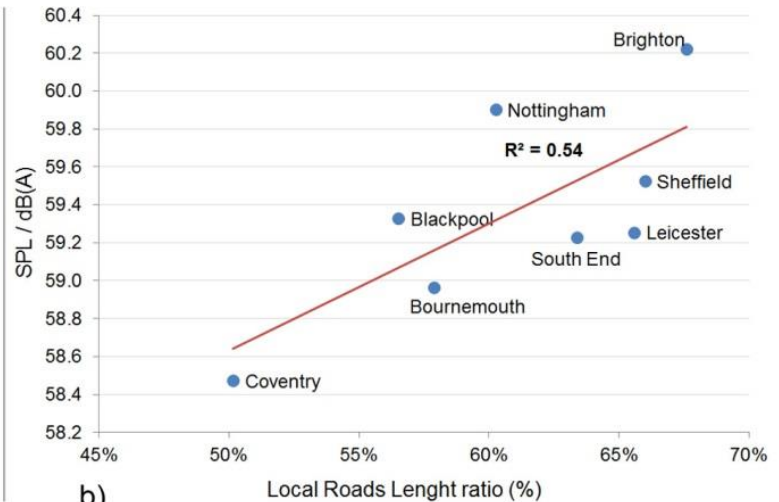

b)

Fig. 6. Statistically significant variables interacting with noise levels in the macro-scale: (a) Negative effect of the ANN $\left(R^{2}=.50\right)$, (b) Positive effect of the Local Roads Length ratio $\left(R^{2}=.54\right)$.

Table 2

Cities of linear and radial typology with noise and green space attributes.

\begin{tabular}{lccccccc}
\hline \multicolumn{1}{c}{ Cities } & $\begin{array}{c}\text { Settlement } \\
\text { form }\end{array}$ & $\begin{array}{c}\text { Noise levels } \\
{[\mathrm{dB}(\mathrm{A})]}\end{array}$ & Natural Urban Green ratio (\%) & ANN & z-score & p-value & Pattern \\
\hline Coventry & radial & 58.47 & 25 & 1.14 & 8.05 & 0 & Dispersed \\
Leicester & radial & 59.25 & 22 & 1.04 & 2.68 & 0 & Dispersed \\
Nottingham & radial & 59.9 & 24 & 0.88 & -11.7 & 0 & Clustered \\
Sheffield & radial & 59.52 & 26 & 1.11 & 7.78 & 0 & Dispersed \\
& & & & & & & Clustered \\
Bournemouth & linear & 58.97 & 21 & 0.93 & -4.29 & 0 & Dispersed \\
Blackpool & linear & 59.33 & 23 & 1.06 & 3.2 & 0 & Clustered \\
Southend & linear & 59.23 & 18 & 0.93 & -3.36 & 0 & Clustered \\
Brighton & linear & 60.22 & 21 & 0.77 & -13.41 & 0 &
\end{tabular}

The scatter plot in Fig. 6a summarizes the results suggesting that an increase in the distance between neighbouring green patches can possibly be correlated with a decrease in traffic noise. Among the eight cities described in Table 2, Brighton presented the lowest value of the index $(A N N=.77)$ and Coventry the highest $(A N N=1.14)$. Secondly, there was a positive correlation between the Local Roads Length ratio and noise levels $r(8)=.73, p<$ .05 presented in Fig. 6b. Brighton and Coventry represent once more the marginal cases with $67.6 \%$ and $50.2 \%$ respectively. This correlation is practically related to higher internal network connectivity. More local roads increase the number of street connections with the Primary and Secondary Network allowing for more cars and higher traffic flows. 
The effect of Green Space Ratio, Green Space Pattern and traffic noise in cities of different settlement form

The assessment of the relationship between Natural Urban Green ratio and the two settlement forms was performed via an independent sample t-test. The assumptions of normality and homogeneity were tested and satisfied. According to the scatterplot in Fig. $7 \mathrm{a}$, it was proved that there was a significant difference in the average values of Natural Urban Green for radial $(\mathrm{M}=.24, \mathrm{SD}=.017)$ and linear cities $(\mathrm{M}=.20, \mathrm{SD}=.021)$; conditions, $\mathrm{t}=$ $2.61, p=.040$. Therefore, it is reasonable to deduce that radial cities are associated with a higher Natural Urban Green ratio compared to linear cities and generalize this conclusion also in other urban areas with similar settlement form in UK. A possible explanation is that linear cities are usually built close to the coastline and tend to develop a denser urban structure with less green areas than mainland cities.
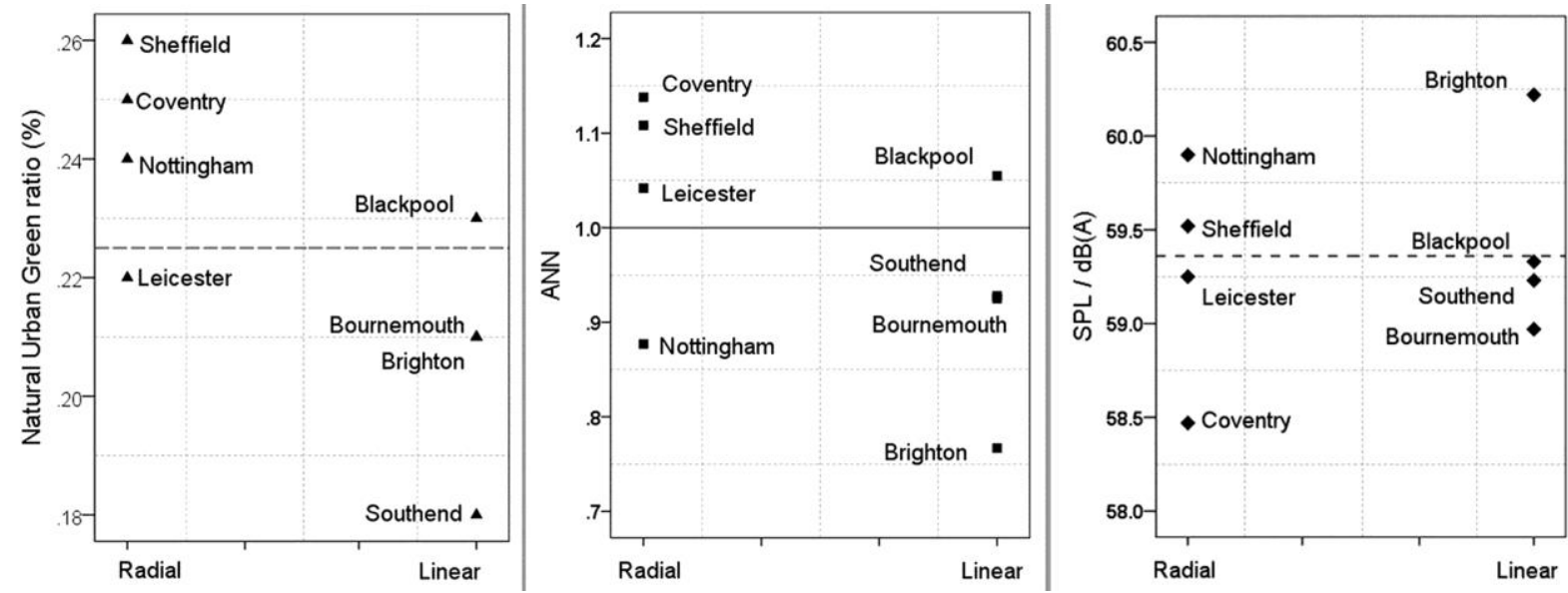

Fig. 7. Dot plots describing the relationship of the two settlement forms with: (a) Natural Urban Green ratio, (b) ANN and (c) Noise levels.

As a result radial cities are more likely to have a lower average $L_{\text {den }}$ than linear cities under the same traffic conditions. The comparison of Green Space Pattern in radial and linear cities was tested using the Conefor index and the ANN index, however only the second one provided statistically significant results. Fig. $7 \mathrm{~b}$ demonstrated that three out of four radial cities tend to follow a dispersed pattern (ANN > 1). With the same proportion, linear cities present a trend towards following a clustered pattern $(A N N<1)$. These tendencies were proved strong, but not statistically significant in the correspondent ANN scores of the t-test ( $t$ $=-1.47, p=.19)$. The reason of those tendencies can be attributed mainly to the local topography since linear cities are usually restricted by physical obstacles (e.g. sea), while radial cities are more flexible in expanding. Overall, these trends can be generalized in other cites of similar settlements, after validating this hypothesis within a bigger sample. According to Fig. 7c, noise levels for radial and linear cities are almost evenly distributed ranging from $58.5 \mathrm{~dB}(\mathrm{~A})$ to $60.2 \mathrm{~dB}(\mathrm{~A})$ with no significant difference between them. The $5 \mathrm{~dB}(\mathrm{~A})$ difference between noise classes reduces the accuracy of the final $L_{\text {den }}$. Nevertheless, these levels should be considered more as an indicative tendency of the whole city, rather than precise values.

Car Availability ratio can also provide useful evidence about the expected noise levels. Results presented in Fig. 8 confirm that three out of four linear cities are above the average value $(M=0.41)$. The overall results from Figs. 7 and 8 increase the probabilities for radial cities to be accredited as "less noisy" than linear cities, in a macroscopic approach. 


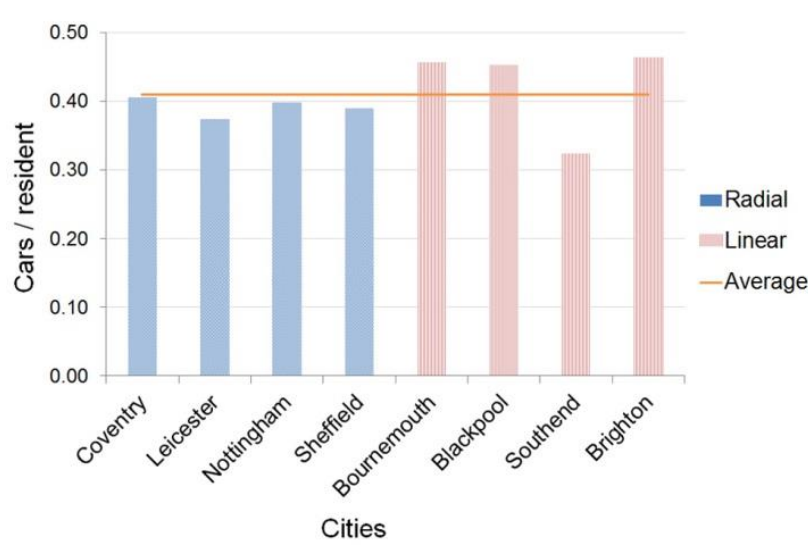

Fig. 8. Car Availability ratio in linear and radial cities.

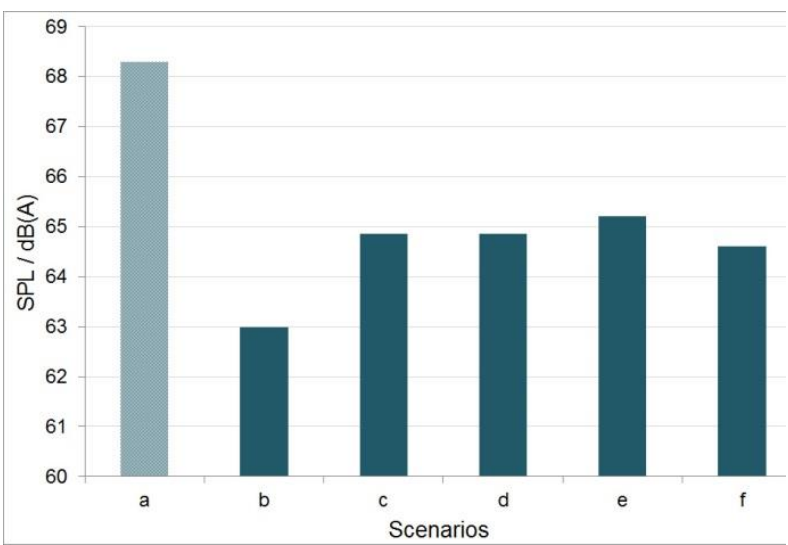

Fig. 10. Average noise levels for the six receivers calculated for every scenario of porous configuration.

\section{Validation of the ANN index}

A simulation using CadnaA software was applied in order to validate the results of the ANN index in the macro-scale approach. Five different scenarios of porous ground arrangements and a reference case with totally rigid ground were tested as presented in Fig. 9. ISO 9613 and CRTN were used as the main protocols in the model. Six receivers were added in stable positions with a distance of $100 \mathrm{~m}$ between them. Finally, a federal road of 50,000 veh/18 $\mathrm{h}$ was used as the unique traffic source. Results in Fig. 10 proved that the highest attenuation in average values among the six receivers was achieved when the green patches were more dispersed (cases c-e) and not clustered (cases b, f). These results confirm in a restricted scale the findings of Fig. $6 \mathrm{a}$, where dispersed patterns are related to lower noise levels.

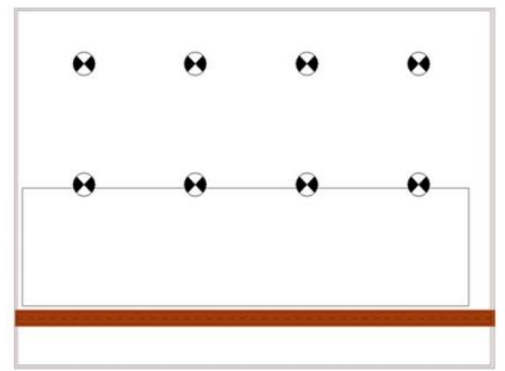

a)

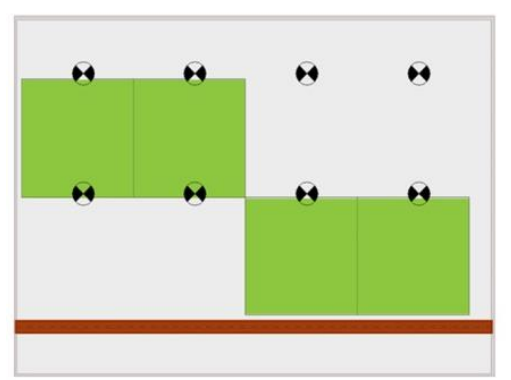

d)

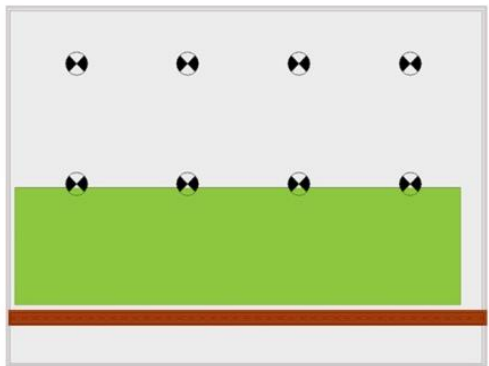

b)

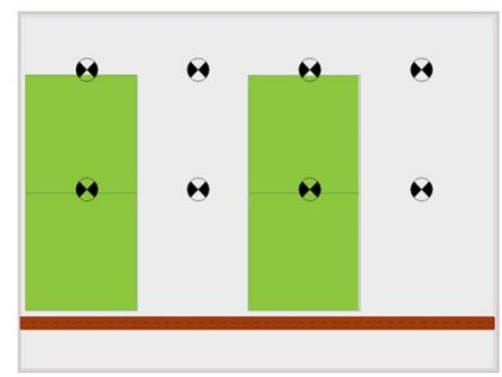

e)

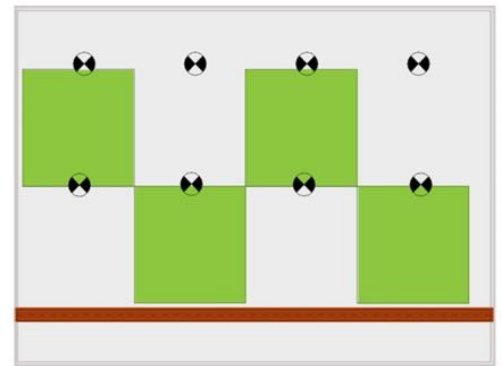

c)

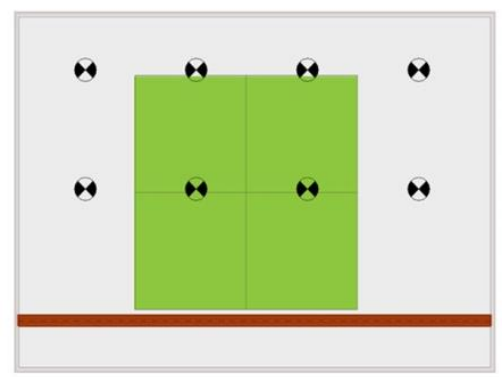

f)

Fig. 9. Reference case (a) and five different configuration scenarios of porous patches (b-f). 
Table 3

Pearson correlation ( $r$ ) and summary results for the regression analysis in Sheffield and Brighton.

\begin{tabular}{|c|c|c|c|c|c|c|c|c|}
\hline & Variables & Pearson $(r)$ & & Model & $\beta$ & $t$ & Sig. & VIF \\
\hline \multirow{5}{*}{$\begin{array}{l}\frac{0}{\frac{0}{d}} \\
\frac{\frac{1}{d}}{\omega}\end{array}$} & Primary Roads Length & & \multirow{5}{*}{ 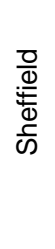 } & (Constant) & 57.26 & 88.23 & .00 & \\
\hline & Building Perimeter & $.67^{* *}$ & & & & & & \\
\hline & Local Road Intersections & $.66^{* *}$ & & Gardens ratio & -.24 & -2.58 & .02 & 1.54 \\
\hline & Gardens ratio & $-.62^{* \star}$ & & Local Road Intersections & .42 & 5.17 & .00 & 1.18 \\
\hline & Natural Urban Green ratio & $-.54^{\star *}$ & & Primary Roads Length & .52 & 5.27 & .00 & 1.76 \\
\hline \multirow{4}{*}{ 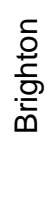 } & Primary Roads Length & $.70^{* *}$ & \multirow{4}{*}{ 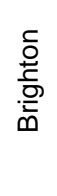 } & (Constant) & 57.92 & 133.3 & .00 & \\
\hline & Local Road Intersections & $.67^{* *}$ & & Car Availability index & .20 & 1.412 & .17 & 1.45 \\
\hline & Car Availability ratio & $.54^{* *}$ & & Local Road Intersections & .25 & 1.81 & .08 & 1.7 \\
\hline & Gardens ratio & $-.61^{* *}$ & & Primary Roads Length & .48 & 4.11 & .00 & 1.215 \\
\hline
\end{tabular}

Meso-scale

Identification and effectiveness of morphological indicators related to traffic noise

The meso-scale analysis presented in Table 3 demonstrated that 6 out of the 18 variables tested (See Table 1), were proved correlated for both cities within the confidence interval of $99 \%$. As far as Sheffield is concerned, positive correlations with noise levels were indicated for the Building Perimeter $r(30)=.67$ and the Local Road Intersections $r(30)=.66$. The proportion of Gardens ratio and Natural Urban Green ratio had a negative correlation with $L_{\text {den, }} r(30)=-.62$ and $r(30)=-.54$ respectively. In Brighton positive correlations were reported for the Local Road Intersections, $r(30)=.67$ and Car Availability $r(30)=.54$, while a negative effect was observed for Gardens ratio, $r(30)=-.61$. Finally both cities had high positive correlations in Primary Roads Length with $r(30)=.82$ and $r(30)=.70$. The positive correlation of Building Perimeter only for Sheffield can be explained by the combination of larger buildings and higher noise levels in the city centre. On the contrary, more distant and less noisy areas tend to present larger building blocks but lower Building Perimeter since houses are smaller. 

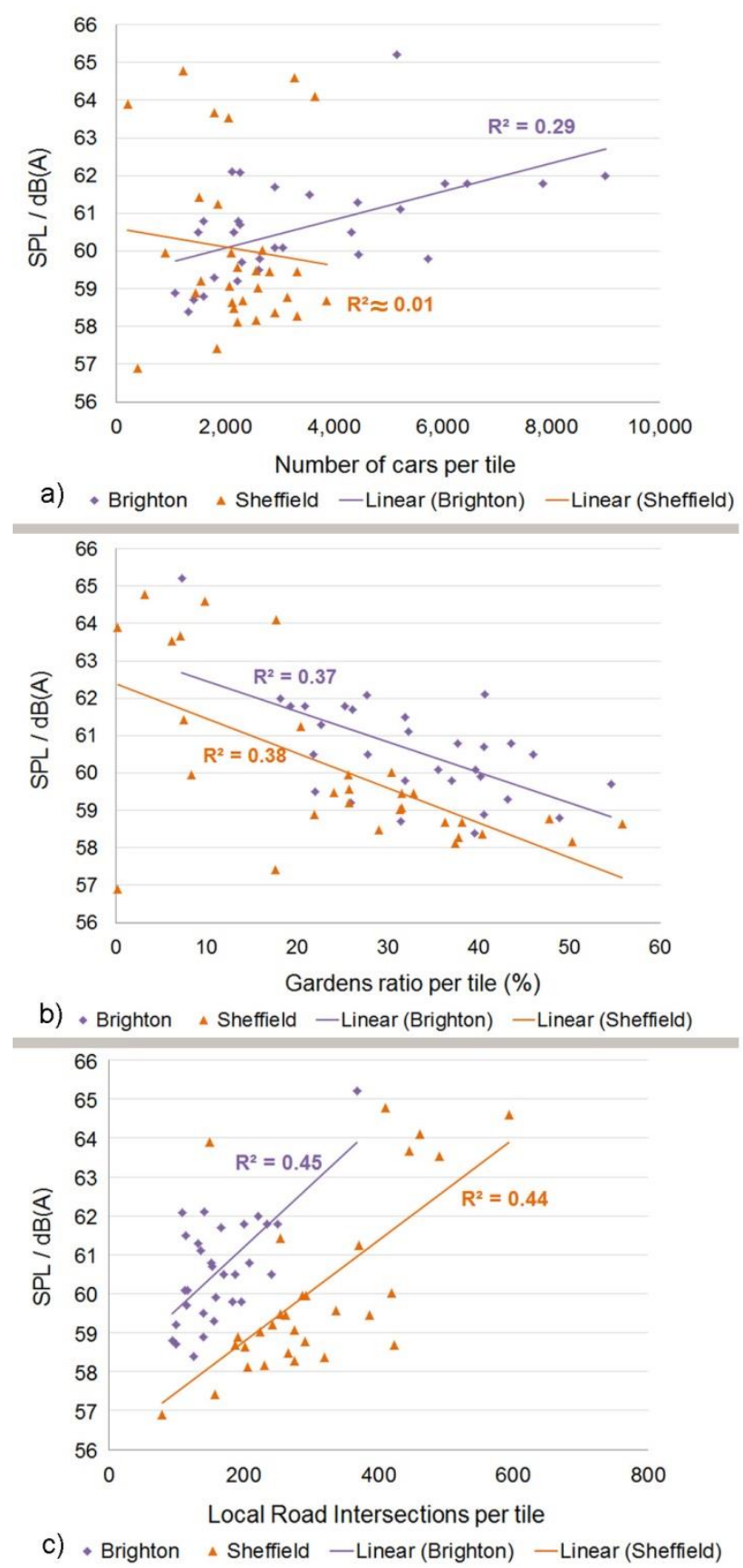

Fig. 11. Linear trend of variables significant in the regression models for Sheffield and Brighton: (a) Car Availability, (b) Gardens ratio, (c) Local Road intersections.

A linear regression analysis was conducted in order to test the effectiveness of the variables in Table 3 as inputs in a noise prediction model for $L_{\text {den. }}$ The multicollinearity diagnostics and the data cleaning process eliminated predictors with Variance Inflation Factor (VIF) higher than 10 (Table 3), a commonly used cut-off value suggested by Myers (1990). It was found that the model in Sheffield explained $85.5 \%$ of the variance $\left(R^{2}=.85\right.$, $F(3,26)=51.2, p<.05)$ using three variables. Among them the Primary Roads Length $(\beta=.52)$ was proved to have the highest impact on noise levels as expected, followed by Gardens ratio $(\beta=-.24)$ and Local Road Intersections $(\beta=.42)$. Accordingly, the regression model in Brighton accounted for $72 \%$ of the total variance $\left(R^{2}=.72, F(3,29)=21.4, p<.05\right)$. Car Availability ratio $(\beta=.20)$ was used instead of Gardens ratio since it had a stronger effect, proving that particular geodemographic metrics can also explain part of the 
variance. Local Road Intersections $(\beta=.25)$ and Primary Roads Length $(\beta=.48)$ were the other two variables contributing in the prediction models.

Fig. 11 presents an individual assessment of the variables included in the regression models apart from the expected effect of Primary Roads Length. This variable reflects the main traffic volume in all cities and as a result it has the primary weight in noise levels. As it can be seen in Fig. 11a Car Availability had an effect on noise levels only for Brighton $\left(R^{2}=.29\right)$ denoting that it can be used as a prediction variable only in certain cases. According to Fig. $11 \mathrm{~b}$ the coefficient of determination for Gardens ratio was higher in Brighton $\left(R^{2}=.37\right)$ than in Sheffield $\left(R^{2}=.28\right)$. This trend can be partly explained by the local urban design, since Brighton has a higher amount of garden terraced houses. Consequently, areas with these housing characteristics are more probable to present lower noise levels in both settlement forms.

Despite the similar Road Coverage ratio in the class of local roads for both cities $(74.4 \%$ and $77.6 \%$ ); an increase in Local Road Intersections is very likely to lead to higher noise levels according to Fig.11c. However the settlement pattern of the city should also be considered. It is characteristic that the city of Sheffield - following a radial settlement - has on average lower noise levels with 8,832 intersections, while Brighton as a linear city has higher noise levels with 4,928 intersections in the same area. In terms of urban structure this fact denotes that the city of Brighton has also larger building blocks and reduced connectivity between the roads.

a)

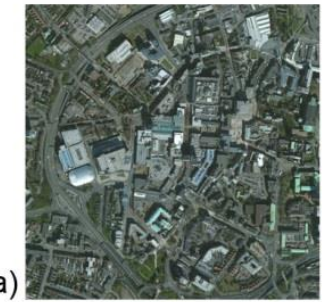

b)

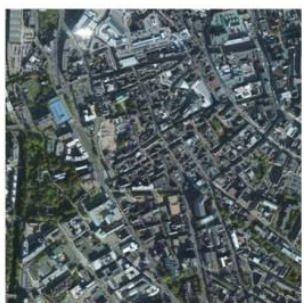

c)

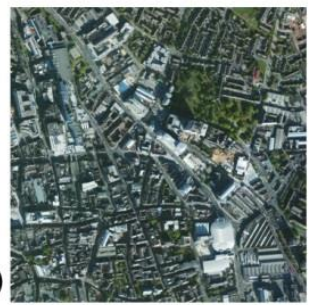

d)

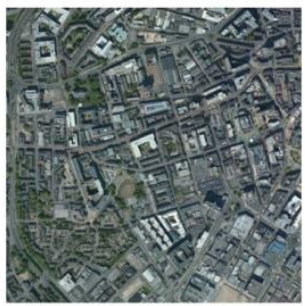

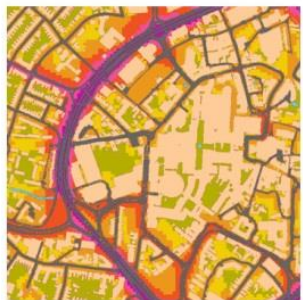
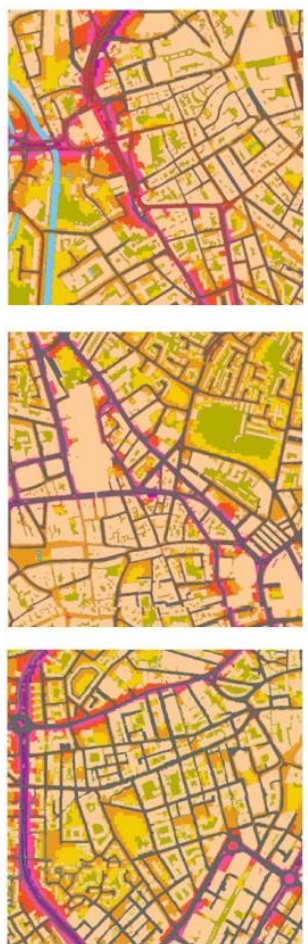

e)
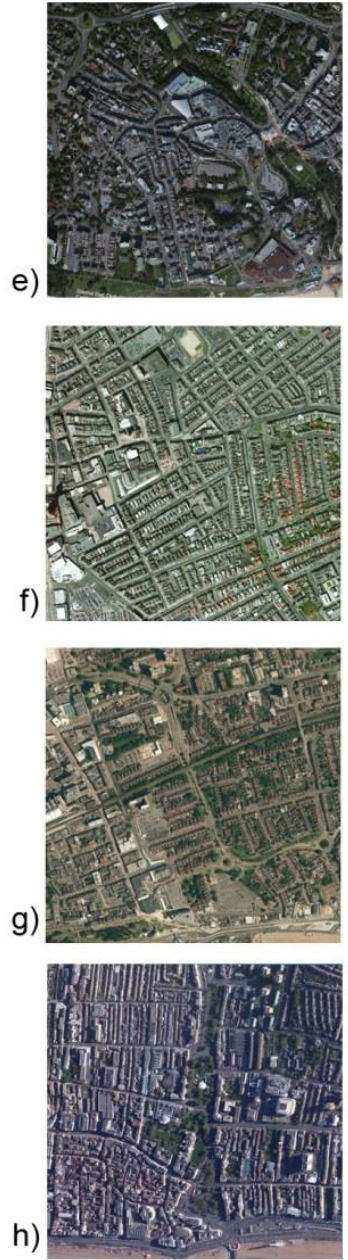
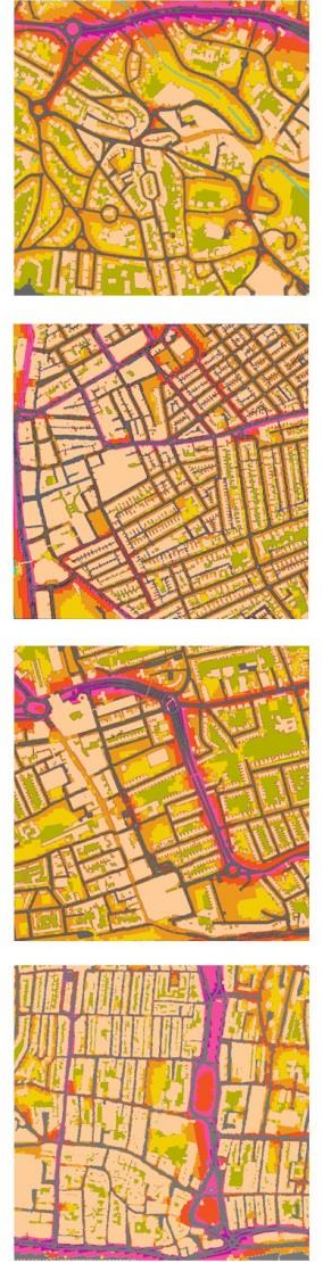

Fig. 12. Radial city centres: (a) Coventry, (b) Leicester, (c) Nottingham, (d) Sheffield/Linear city centres: (e) Bournemouth, (f) Blackpool, (g) Southend, (h) Brighton. 

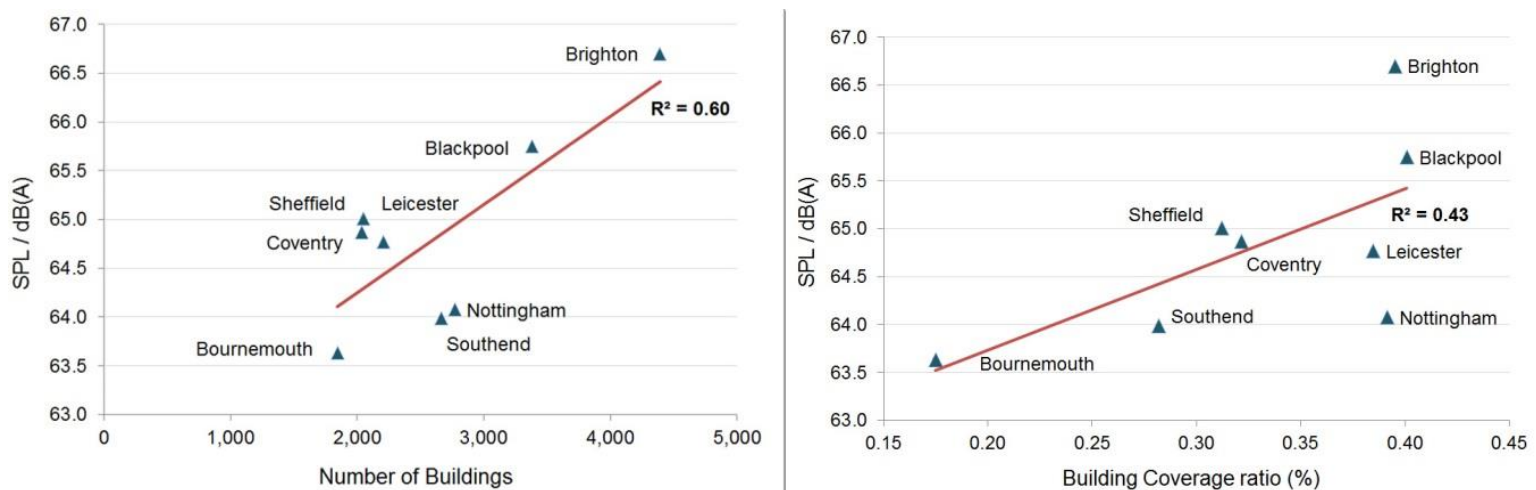

Fig. 13. Linear association between noise levels and: (a) Number of Buildings $\left(R^{\llcorner}=.60\right.$, (b) Building Coverage ratio $\left(R^{2}=.43\right)$.

\section{Micro-scale}

\section{Comparison among the city centres}

The final level of analysis included eight city centres as presented in Fig. 12. A Pearson correlation among the 18 variables (see Table 1) revealed that there was a significant positive correlation only with the Number of Buildings $(r=.84, p<.01)$ as it is presented in Fig. 13a. Consequently city centres with more buildings experience higher noise levels.

The building coverage was also investigated as a complementary factor related to the Number of Buildings. However, Fig. 13b proves that Building Coverage ratio itself is not enough in order to end up with a solid conclusion, since areas with similar index values can experience different noise levels.

Table 4

Cluster membership of the city centres according to the k-means algorithm.

\begin{tabular}{lll}
\hline Cities & Cluster & Distance \\
\hline Brighton & 1 & 2,514 \\
Blackpool & 1 & 7,872 \\
Leicester & 1 & 8,583 \\
Nottingham & 1 & 1,605 \\
Southend & 2 & 23,197 \\
Sheffield & 2 & 6,726 \\
Coventry & 2 & 16,471 \\
Bournemouth & 3 & 0 \\
\hline
\end{tabular}

A k-means algorithm was then applied in order to identify pairs of cities with similar attributes based on the Number of Buildings, the Building Coverage ratio and the noise levels. Results according to the cluster membership in Table 4 proved that the first group includes the centres of Brighton, Blackpool, Leicester and Nottingham. These places appear to have similar values of Building Coverage ratio, but different noise levels (Fig. 13b). Apparently, Brighton and Blackpool have the highest ranking both in Building Coverage ratio and in the Number of Buildings. From an architectural viewpoint, the Regency type in Brighton and the heavy Victorian influence in Blackpool have both affected to some extent these tendencies with the long building blocks and the dense terraced houses. Leicester and Nottingham have similar Building Coverage ratio thanks to the greater and more ponderous buildings. These centres are highly affected by the Baroque and Renaissance style with some Victorian influences as well. 
In the second group, city centres such as Southend, Sheffield and Coventry were clustered together. These city centres have significantly lower Building Coverage ratio and Number of Buildings while varying in population dynamic. All of them are influenced by the Victorian architecture and their centres especially in Sheffield and Coventry consist mainly of traditional semi-detached or terraced houses combined with post-war high rise flats. Finally, the city centre of Bournemouth presented the lowest levels in all the previous indexes, forming a cluster itself. Due to the late rise in its population and enhanced by the fact that it has the greatest percentage of green space coverage among the other centres, it is currently the place with the lowest noise levels. Overall, it was clear that noise levels in the city centres do not seem to correspond to the population evolution or the car availability of these cities. On the contrary, they were more related to building attributes and the relevant architectural influences, which affected their current style.

\section{Discussion: Planning implications at different scales}

Measurable metrics and quantitative statistical analysis were used to assess the relationship between green spaces in urban areas and other features of urban morphology with traffic noise distribution. For this purpose cities of different settlement forms were analyzed in a triple-scale approach with different implications at each scale.

\section{Implications in the macro-scale}

In a macro-scale level, urban sound planning policies can be more targeted when considering the settlement profile of the city. The first evidence for both settlement forms is that scattered green spaces can possibly enhance noise attenuation not only due to their physical characteristics, but also due to the fact that they restrict high population densities and car usage (Moudon, 2009). However, the fact that linear cities have more probabilities to be "noisier" suggests that in such places noise mitigation measures may require a higher budget or more traffic calming interventions. By all means, the Green Space Pattern needs further validation in more cities of similar settlement form. The effort to classify various cities according to their settlement form does not set a rigid rule for the expected noise levels. In the current analysis evidence towards characterizing linear cities as "more noisy" was given by their higher ratio of Road Coverage and Primary Roads Length. The average $L_{\text {den }}$ levels and the Car Availability ratio also appear to be higher in this settlement type, despite the similar population in all cities.

\section{Implications in the meso and micro-scale}

Previous studies which investigated the connection between urban morphology and traffic noise have shown that a high number of street intersections is combined with fewer vehicle miles travelled (Knaap et al., 2005) and lower noise levels (Tang and Wang, 2007; ArizaVillaverde et al., 2014). Results in Sheffield and Brighton, give rise to opposite conclusions probably because of the different scale of analysis and the methodology for noise level calculation. The fact that Natural Urban Green ratio was not statistically significant in Brighton as in Sheffield does not underestimate the importance of this variable in urban sound planning (De Ridder et al., 2004), but is rather related to the methodology and the input data used. Possible solutions for active noise control should involve land use and transportation planning in parallel with traffic calming measures. So far noise abatement techniques involve the application of buffer zones and land use compatibility plans especially close to highways. This last measure is already a reality in many cities and these policies 
can save millions per year from noise barriers construction (Pinckney, 2005). Effective tools for urban planning strategies with simultaneous increase of green spaces were developed in the BUGS project (BUGS, 2001). Examples of effective land use control with simultaneous traffic calming effects can also be found in the "garden city movement" (Howard, 1902). UK cities such as Milton Keynes, Glenrothes and Telford following this pattern combine a singleuse zoning plan emphasizing on green space distribution and sinuous roads configuration.

The relationship between the ANN index and green patches suggests that green spaces are likely to become more accessible in a dispersed pattern. However, this configuration does not always end up in lower noise levels (Ståhle, 2010). On the other hand every revitalization plan should also focus on its gentrification effects when property values rise to such an extent that local residents are led to displacement (Wolch et al., 2014). Low levels of traffic noise were also observed in areas with terraced houses of small perimeter accompanied by a backyard or front yard. Consequently this housing pattern presents high noise effectiveness in residential areas.

In the micro-scale level, results proved that the same building density achieved with different number of buildings can infer diverse traffic noise effects. Specifically, more buildings are related to higher noise levels, in spite of the fact that there is evidence for the opposite in particular cities (Salomons and Berghauser Pont, 2012). Planning strategies in the city centres should be more oriented towards traffic and soundscape interventions, since the built environment is highly unchangeable. In this process the applied trends in domestic architecture for noise mitigation should also be considered.

\section{Implications in all scales}

The common variables identified in these scales can be summarized in street characteristics (connectivity, hierarchy), land use and geodemographic attributes. There is also an indication that the Green Space Pattern can possibly affect noise levels in conjunction with the above parameters. The absence of correlation in Natural Urban Green ratio or Gardens ratio on the macro-scale suggests that some variables might be scale or grid-dependent, consequently their significance has to be cross-validated in different scales. Overall, since traffic noise attenuation is a multi-disciplinary issue, morphological and geodemographic parameters should be considered in accordance with traffic calming measures. Complementary actions involving masking of the traffic with natural sounds such as bird songs (Strohbach et al., 2009; Hao et al.; 2015b) are also useful.

\section{Restrictions and future investigation}

In the overall process, restrictions such as the aggregation effect caused by the grid size should be taken into account in future investigation. In spite of the $5 \mathrm{~dB}(\mathrm{~A})$ range in each noise band, the accuracy is not critically affected within an urban scale analysis. A possible decrease of this error can be tested by applying a raster-based approach in GIS or by decreasing the grid size. A further validation of the current results in other cities of similar settlement type can make the findings more coherent and drive to a paradigm shift as regards the optimization of noise levels according to different criteria.

\section{Conclusions}

The purpose of this study was to investigate the relationship between traffic noise distribution and urban morphology in eight UK cities of different settlement forms. Land use parameters emphasizing on green spaces - combined with buildings, roads and 
demographic attributes - were quantified using GIS and statistical analysis tools in a triple level approach. In a first macro-scale level, four cities of radial settlement form were compared with four cities of linear form. In the second meso-scale level, a more thorough investigation of the same parameters was conducted between two cities from the above categories. In the final micro-scale level the analysis was focused only on the eight city centres. The historical and architectural background of the cities was also taken into consideration. Conclusions can be summarized as follows:

- The macro-scale analysis shows that radial and linear cities are usually liable to a different Green Space Pattern. The distribution of Natural Urban Green spaces can be a possible reason affecting noise levels throughout the cities. In particular, a dispersed Green Space Pattern combined with the proper road and building attributes - under similar traffic conditions - is positive evidence for lower noise levels, in contrast with a clustered one. Secondly, higher internal network connectivity caused by an increase in the Local Roads Length ratio, is also connected to higher traffic noise levels, since more connections are created along the network. The range of these variables is different when comparing cities of different settlement form.

- The radial cities in this investigation were associated with a significantly higher Natural Urban Green Ratio than linear cities, allowing for a generalization of this conclusion also to other urban areas with similar settlement forms in UK. Moreover, the majority of radial cities follows a dispersed green pattern, while the majority of linear cities follows a clustered one. The previous two conclusions and the fact that dispersed patterns were related to lower noise levels in these settlements leads to the indirect inference that radial cities are more likely to be "quieter" than linear cities under similar traffic and demographic conditions.

- Six morphological variables were proved to be related to traffic noise levels in the mesoscale analysis between Brighton and Sheffield (Table 3). In Sheffield, an increase in Building Perimeter, the Local Road Intersections or the Primary Roads Length can infer a rise in traffic noise levels. On the contrary, land use variables such as Gardens ratio or Natural Urban Green ratio were proved to be negatively related to traffic noise. From the above parameters Local Road Intersections and Primary Roads Length were proved significant also in Brighton followed by Car Availability ratio. Ultimately, a prediction model for traffic noise was calculated for each city. The two models managed to explain successfully more than $70 \%$ of the variance proving that traffic noise prediction for urban areas can be based to a great extent on common morphological variables.

- In the micro-scale level, out of all the variables tested, only the Number of Buildings was proved correlated to noise levels. The Building Coverage ratio was investigated as a complementary variable. Three classification groups were formed according to the historical and architectural background of each city centre. Places in the first group (Brighton, Blackpool, Leicester Nottingham) were typical of similar Building Coverage either affected by Regency and heavy Victorian influences or by Baroque and Renaissance style. The three places in the second group (Southend, Sheffield, Coventry) were typical of lower Building Coverage and noise levels characterized by post war and modern architecture. Finally, the city centre of Bournemouth with the most recent history and the lowest noise levels was classified alone with a significant distance from the other groups.

Generally, it was revealed that in order to reduce traffic noise levels, based on the case studies in typical UK cities it is essential to take into consideration different parameters of 
urban morphology. Green spaces, road and building attributes should be combined with the housing types and the local architectural tendencies. Demographic variables can also provide evidence of the expected noise levels; however they are not always reliable. Finally, the comparison among different UK cities can be consistent and provide a stable noise prediction model especially if accompanied by a common input dataset for all the variables.

\section{Acknowledgements}

This research received funding from the People Programme (Marie Curie Actions) of the European Union's Seventh Framework Programme FP7/2007-2013 under REA grant agreement n॰290110, SONORUS “Urban Sound Planner". 


\section{References}

Ariza-Villaverde, A.B., Jiménez-Hornero, F.J., Gutiérrez De Ravé, E., 2014. Influence of urban morphology on total noise pollution: multi fractal description. Sci.Total Environ. 472, 1-8.

Attenborough, K., 2002. Sound propagation close to the ground. Annu. Rev. Fluid Mech. 34, 51-82, http://dx.doi.org/10.1146/annurev.fluid.34.081701.143541.

Attenborough, K., Taherzadeh, S., Bashir, I., 2012. HOSANNA, Deliverable 4.5,predicted effects of porous surfaces, technical report HSNNA 45 TRP 20121026 OPU10.

Bashir, I., Taherzadeh, S., Shin, H.-C., Attenborough, K., 2015. Sound propagation over soft ground without and with crops and potential for surface transport noise attenuation. J. Acoust. Soc. Am. 137, 154-164, http://dx.doi.org/10.1121/1.4904502.

Chakraborty, M., Master thesis 2009. An approach towards urban form analysis and land use classification: a case of Ahmedabad, India. International Institute of Geo-information Science and Earth Observation, Enschede, Netherlands.

Cohen, P., Potchter, O., Schnell, I., 2014. A methodological approach to the environmental quantitative assessment of urban parks. Appl. Geogr. 48,87-101.

De Ridder, K., Adamec, V., Bañuelos, A., Bruse, M., Bürger, M., Damsgaard, O., Dufek,J., Hirsch, J., Lefebre, F., Pérez-Lacorzana, J.M., Thierry, A., Weber, C., 2004. An integrated methodology to assess the benefits of urban green space. Sci. Total Environ. 334-335, 489-497, http://dx.doi.org/10.1016/j.scitotenv.2004.04.054.

European Directive 2002/49/EC of the European Parliament and of the Council of25 June 2002 relating to the assessment and management of environmental noise (END)., 2002. Official Journal of the European Communities L189, 12-25.

European Commission, 2007. Working group assessment of exposure to noise(WG-AEN). Position paper good practice guide for strategic noise mapping and the production of associated data on noise exposure, version 2. Brussels.,pp. 82.

Fang, C.F., Ling, D.L., 2005. Guidance for noise reduction provided by tree belts. Landsc. Urban Plan. 71 (1), 29-34.G-Power manual, 2014. Version 3., 1.

Galster, G., Hanson, R., Ratcliffe, M.R., Wolman, H., Coleman, S., Freihage, J., 2001.Wrestling sprawl to the ground: defining and measuring an elusive concept. Hous. Policy Debate 12 (4), 681-717.

Gołebiewski, R., 2007. Simple methods for determination of the acoustical properties of ground surfaces. Arch. Acoust. 32, 827-837.

González-Oreja, J.A., Bonache-Regidor, C., De La Fuente-Díaz-Ordaz, A.A., 2010. Far from the noisy world? Modelling the relationships between park size, tree cover and noise levels in urban green spaces of the city of Puebla, Mexico.Interciencia 35, 486-492.

Guedes, I.C.M., Bertoli, S.R., Zannin, P.H.T., 2011. Influence of urban shapes on environmental noise: a case study in Aracaju-Brazil. Sci. Total Environ.412-413, 66-76.

Hao, Y., Kang, J., 2013. Traffic resistance of low-density residential areas in context of urban morphology. In: AIA-DAGA, Conference on Acoustics, Merano, 18-21March.

Hao, Y., Kang, J., Krijnders, D., Wörtche, H., 2015a. On the relationship between traffic noise resistance and urban morphology in low-density residential areas. Acta Acust. United with Acust. 101, 510-519, http://dx.doi.org/10.3813/AAA.918848.

Hao, Y., Kang, J., Krijnders, J.D., 2015b. Integrated effects of urban morphology on birdsong loudness and visibility of green areas. Landsc. Urban Plan. 137,149-162, http://dx.doi.org/10.1016/..landurbplan.2015.01.006.

Haq, S.M.A., 2011. Urban green spaces and an integrative approach to sustainable environment. J. Environ. Prot. 02, 601-608, http://dx.doi.org/10.4236/jep.2011.25069.

Horoshenkov, K., Khan, A., Benkreira, H., 2013. Acoustic properties of low growing plants. J. Acoust. Soc. Am. 133, 2554-2565, http://dx.doi.org/10.1121/1.4798671.

Howard, E., 1902. Garden Cities of tomorrow. S. Sonnenschein \& Co., Ltd., London. Huddart, L., 1990. The use of vegetation for traffic noise screening. UK transport and road research laboratory research report. Crowthorne, England.

ISO 9613-2, 1996. Acoustics-attenuation of sound during propagation outdoors -Part 2: General method of calculation. International Organization for Standardization, Geneva, Switzerland.

Kang, J., 2007. Urban Sound Environment. Taylor and Francis, London and New York.

Kashem, S.B., Chowdhury, T.A., Rahman, J.M., 2009. Quantifying urban form: A Case Study of Rajshahi City. J. Bangladesh Inst. Plan. 2, 39-48.

Knaap, G.J., Song, Y., Nedovic-Budic, Z., 2005. Measuring patterns of urban development: new intelligence for the war on sprawl. Local Environ. 12 (3),239-257. 
Kragh, U.J., 1981. Road traffic noise attenuation by belts of trees. Int. J. Agric.Biosyst. Sci. Eng. 74 (2), 235241.

Kropf, K., 2005. The handling characteristics of urban form. Urban Des., 17.

Lam, K.C., Ma, W., Chan, P.K., Hui, W.C., Chung, K.L., Chung, Y.T., Wong, C.Y., Lin, H.,2013. Relationship between road traffic noise scape and urban form in Hong Kong. Environ. Monit. Assess. 185 (12), 96839695.

Lee, P.J., Kang, J., 2015. Effect of height-to-width ratio on the sound propagation in urban streets. Acta Acust. united with Acust. 101, 73-87, http://dx.doi.org/10.3813/AAA.918806.

Liu, J., Kang, J., Behm, H., Luo, T., 2014. Landscape spatial pattern indices and soundscape perception in a multi-functional urban area, Germany. J. Environ.Eng. Landsc. Manag. 22, 208-218, http://dx.doi.org/10.3846/16486897.2014.911181.

Lynch, K., Hack, G., 1962. Site Planning, 1st ed. MIT Press, Cambridge, MA/London.

Margaritis, E., Aletta, F., Axelsson, Ö., Kang, J., Botteldooren, D., Singh, R., 2015.Soundscape mapping in the urban context: a case study in Sheffield. In: AESOP Conference, Prague, 13-16 July.

Marshall, Stephen., 2005. Street and Patterns. Spon Press, London/New York.

Marshall, S., Gong, Y., 2009. WP4 Deliverable Report: Urban pattern specification, Bartlett School of Planning. University College London, Retrieved from http://www.suburbansolutions.ac.uk/documents/WP4DeliverableReportNov2009.pdf (23.10.13).

McGarical, K., Marks, B.J., 1994. FRAGSTATS: Spatial pattern analysis program for quantifying landscape structure. Forest Science Department, Oregon State University, Corvallis.

Moudon, A.V., 2009. Real noise from the urban environment. How ambient community noise affects health and what can be done about it. Am. J. Prev.Med. 37, 167-171, http://dx.doi.org/10.1016/j.amepre.2009.03.019.

Myers, R., 1990. Classical and Modern Regression with Applications, 2nd ed.Duxbury, Boston, MA.

Nilsson, M.E., Berglund, B., 2006. Soundscape quality in suburban green areas and city parks. Acta Acust. United Acust. 92, 903-911.

Oliveira, M.F., Silva, L.T., 2010. How urban noise can be influenced by the urban form. Adv. Biol. Bioeng. Environ.

Pathak, V., Tripathi, B.D., Mishra, V.K., 2011. Evaluation of anticipated performance index of some tree species for green belt development to mitigate traffic generated noise. Urban For. Urban Green. 10 (1), 61-66.

Pinckney, E., 2005. Improving coordination with local planners. Ohio program looks at results. TR NEWS, 3334.

Quis, D., 1999. Exposure to nocturnal road traffic noise: sleep disturbance and its after effects. Noise Health 4, 11-36.

Salomons, E., Berghauser Pont, M., 2012. Urban traffic noise and the relation to urban density, form, and traffic elasticity. Landsc. Urban Plan. 108 (1),2-16.

Saura, S., Torné, J., 2009. Conefor Sensinode 2.2: A software package for quantifying the importance of habitat patches for landscape connectivity. Environ. Model.Softw. 24, 135-139, http://dx.doi.org/10.1016/j.envsoft.2008.05.005.

Silva, L.T., Oliveira, M., Silva, J.F., 2014. Urban form indicators as proxy on the noise exposure of buildings. Appl. Acoust. 76, 366-376.

Ståhle, A., 2010. More green space in a denser city: critical relations between user experience and urban form. Urban Des. Int. 15, 47-67, http://dx.doi.org/10.1057/udi.2009.27.

Strohbach, M.W., Haase, D., Kabisch, N., 2009. Birds and the city: urban biodiversity, land use, and socioeconomics. Ecol. Soc. 14, URL http://www.ecologyandsociety.org/vol14/iss2/art31/.

Tang, U.W., Wang, Z.S., 2007. Influences of urban forms on traffic-induced noise and air pollution: results from a modelling system. Environ. Model. Softw. 22(12), 1750-1764.

Tsai, Y.-H., 2005. Quantifying urban form: compactness versus "sprawl". Urban Stud. 42, 141-161, http://dx.doi.org/10.1080/0042098042000309748.

Van Renterghem, T., Botteldooren, D., 2002. Effect of a row of trees behind noise barriers in wind. Acta Acust. United Acust. 88, 869-878.

Van Renterghem, T., Attenborough, K., Maennel, M., Defrance, J., Horoshenkov, K.,Kang, J., Bashir, I., Taherzadeh, S., Altreuther, B., Khan, A., Smyrnova, Y., Yang,H.-S., 2014. Measured light vehicle noise reduction by hedges. Appl. Acoust. 78,19-27, http://dx.doi.org/10.1016/j.apacoust.2013.10.01.

Wang, B., Kang, J., 2011. Effects of urban morphology on the traffic noise distribution through noise mapping: a comparative study between UK and China. Appl. Acoust. 72 (8), 556-568. 
Wolch, J.R., Byrne, J., Newell, J.P., 2014. Urban green space, public health, and environmental justice: The challenge of making cities "just green enough. Landsc. Urban Plan. 125, 234-244, http://dx.doi.org/10.1016/..landurbplan.2014.01.017.

Wong, N.H., Kwang Tan, A.Y., Tan, P.Y., Chiang, K., Wong, N.C., 2010. Acoustics evaluation of vertical greenery systems for building walls. Build. Environ. 45,411-420, http://dx.doi.org/10.1016/i.buildenv.2009.06.017.

World Health Organization (WHO), 2011. Burden of disease from environmental noise, quantification of healthy life years lost in Europe. WHO Regional Office for Europe, Copenhagen, Denmark, Retrieved from http://www.euro.who.int/data/assets/pdf file/0008/136466/e94888.pdf (18.12.14).

Yang, H.S., Kang, J., Cheal, C., 2011. Sound dispersion and reverberation by a singletree. In: Internoise, Osaka, 4-7 September.

\section{Further reading (with label)}

DEFRA, 2007. Noise mapping England, Maps and Charts, Retrieved from http://services.defra.gov.uk/wps/portal/noise (12.08.15).

BUGS, 2001. Benefits of Urban Green Space (BUGS) project, Denmark, Retrieved from http://www.ruhr-unibochum.de/bugs/description.htm (03.09.15).

Local histories, 2015. The history of British and Irish towns and cities, Retrieved from http://www.localhistories.org/locallist.html(15.09.15).

Office for National Statistics, 2011. Census Data for England and Wales, Retrieved from https://www.nomisweb.co.uk/census/2011/key statistics (19.08.15).

Ordnance Survey, 2007. OS Mastermap Topography layer, Retrieved from http://digimap.edina.ac.uk/ (12.09.14).

Ordnance Survey, 2014. OS MasterMap Topography Layer: user guide and technical specification., pp. 67, Retrieved from http://www.ordnancesurvey.co.uk/docs/technical-specifications/os-mastermap-itn-layertechnical-specification.pdf (20.12.14).

Sheffield City Council, 2010. Sheffield's great outdoors, green and open space strategy 2010-2030, Retrieved from https://www.sheffield.gov.uk/out-about/parks-woodlands-countryside/green-and-openspace-strategy.html (14.11.14). 